\title{
Stakeholders in curriculum development - case of Supply Chain and Logistics programme
}

\section{Jure Erjavec}

Department for business informatics and logistics, School of Economics and Business, University of Ljubljana, Slovenia.

\begin{abstract}
Higher education institutions involve various groups of stakeholders that can affect strategic and operational actions in various ways and extents. Understanding the relevance of particular stakeholders in regard to an organization is therefore of key importance. Previous research has shown the importance of involvement of different groups of stakeholders in the curriculum development. The main purpose of this paper is to present a conceptual framework for inclusion of various stakeholders in curriculum development cycle for graduate business programmes. This is done by applying the stakeholder map to curriculum development cycle to form the conceptual framework. The framework is then applied to a case of a Supply Chain and Logistics graduate programme curriculum development.
\end{abstract}

Keywords: Stakeholder theory; curriculum management; curriculum development; higher education institution; business logistics; supply chain management. 


\section{Introduction}

Higher education institutions (HEI) involve various groups of stakeholders, from internal such as students and faculty staff, to external such as various governmental entities, donors, communities, competitors, employers etc. (Jongbloed et al., 2008). These stakeholder groups can affect or are affected by the organization's purpose and strategic goals (Freeman, 2010). Different groups of stakeholders can affect strategic and operational actions in various ways and extents (Jongbloed et al., 2008). Understanding the relevance of particular stakeholders in regard to an organization is therefore of key importance to managers and policy-makers (Chapleo \& Simms, 2010).

Curriculum development is a set of processes that involves many academic and professional stakeholders, who are crucial at identifying competencies of the graduates (Al-Jubran, 2020). Previous research has shown the importance of involvement of different groups of stakeholders in the curriculum management. While some studies give special attention to specific activities such as curriculum development (Matkovic et al., 2014), others focus more on specific delivery methods such as e-learning (Wagner et al., 2008) or specific industries (Lagoke et al., 2020). The latter should be further emphasized as different knowledge domains might require different groups of stakeholders with multiple agendas involved in curriculum development. This is also important because curriculum development can be costly, risky as a strategy and potentially time consuming, while on the other hand the directly and indirectly derived benefits can be far higher than the investments (Khan \& Law, 2015). Therefore, identifying key stakeholders for participation in curriculum development is crucial.

The main purpose of this paper is to develop a conceptual framework for inclusion of various stakeholders in curriculum development cycle for graduate business programmes. This is done by applying the stakeholder map to curriculum development cycle by using an example of a Supply Chain and Logistics graduate programme development, where different groups of stakeholders are involved in the curriculum development process.

The structure of the paper is as follows: in the next section the central concepts of curriculum management and stakeholders in higher education are presented. This is followed by developing a conceptual framework of stakeholder mapping on curriculum development and applying it to a case of a graduate Supply Chain and Logistics programme in the third section of the paper. In the conclusion of the paper the limitations and further research ideas are presented. 


\section{Stakeholder involvement in curriculum development}

Curriculum management is defined as a collection of the school's processes and organization for development, design, and implementation of programme's structure, organization, content, assessment of outcomes, pedagogy etc., and should be soundly managed with faculty engaged in the ownership of the process, while fostering and promoting innovation (AACSB International, 2020).

One of the major processes in the curriculum management is how the curriculum is planned, implemented and evaluated (Ornstein \& Hunkins, 2009). Several different approaches can be used for curriculum development. In this paper a widely used and adopted curriculum development model is used: the ADDIE model (Morrison et al., 2019) which consists of five phases: analyze, design, develop, implement and evaluate. This approach is used throughout various fields from natural and social sciences. The model is shown in Figure 1.

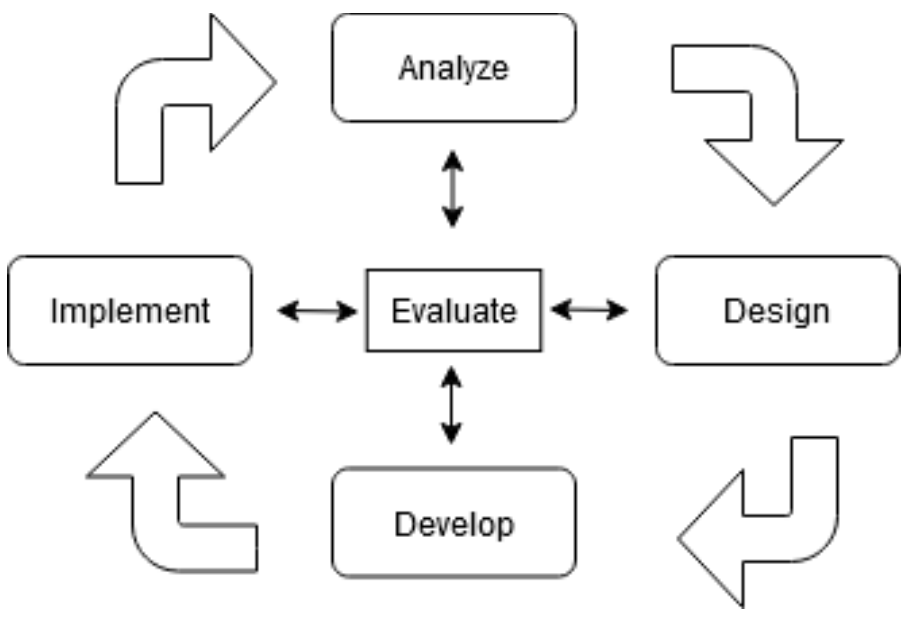

Figure 1. ADDIE model of curriculum development. Source Morrison et al. (2019).

In the analysis phase the current situation is assessed, the needs of the learners are evaluated and learning goals and objectives are defined. This is followed by design phase where an overview of the course or programme design is developed and a blueprint created. The development phase consists of concrete practical plans that follow the generally defined scope in the design phase. In the implementation phase the course or programme is delivered. In the evaluation phase the feedback is obtained and adjustments to the programme and the courses are made. In practice, the evaluation phase is being executed continuously throughout the entire curriculum development process which enables partial loops to be executed, for example analyze and design loop before going to the development phase.

Kettunen (2015) developed a stakeholder map for higher education institutions where key stakeholders are separated into internal and external stakeholders. The map is shown in 
Figure 2. Internal stakeholders include personnel of the HEI and its students, while external stakeholders are classified into partners and customers groups. Furthermore, the stakeholders are separated into four perspectives: process and collaboration, external impact, financial perspective, and organizational learning perspective. All groups of stakeholders are identified as providing an important feedback on curriculum development, regardless whether they are internal or external and which of the aforementioned perspectives they apply to.

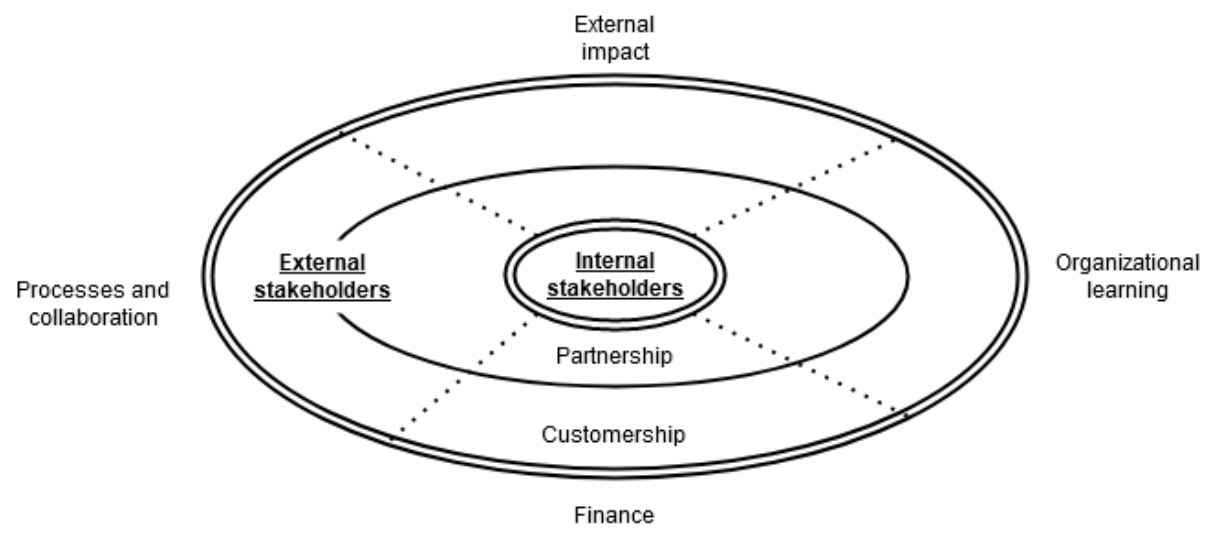

Figure 2. Stakeholder map. Source Kettunen (2015).

Previous research (Matkovic et al., 2014) has shown the importance of stakeholders involved in curriculum development, while also developing a process model tool for identifying them. Other authors (Khan \& Law, 2015) have pointed out the importance of inclusion and participation of all interested stakeholders in the curriculum development. Documented approaches including stakeholder inclusion in curriculum development have been used in several different fields such as nursing and health sciences, engineering, biomedicine, tourism, hospitality and events education and others (Benckendorff et al., 2012; Fagrell et al., 2020; Keogh et al., 2010).

As stakeholder involvement is important through phases of curriculum development, the necessity for mapping the appropriate stakeholders on each of the phases arises. Therefore, the next section presents a conceptual framework for mapping stakeholders through all the five stages of curriculum development and applies it to a case of Supply Chain and Logistics graduate programme.

\section{Conceptual framework and case discussion}

In this chapter the conceptual framework of stakeholder mapping on curriculum development stages is described, which is proposed based on the ADDIE model and the stakeholder map presented in previous chapter. Then it is followed by an example of a graduate Supply Chain and Logistics programme. 
Stakeholders involved in curriculum development are key informers and drivers of the content, methods of delivery, evaluation requirements and the scope of curriculum that qualifies for a certain profession (Matkovic et al., 2014). It is therefore essential that they are identified and assigned to the appropriate phase of the curriculum development process with their role clearly defined, before the process is executed. The conceptual model is shown in Figure 3. What this model emphasizes is that each of the curriculum development stages needs to have its specific stakeholders involved.

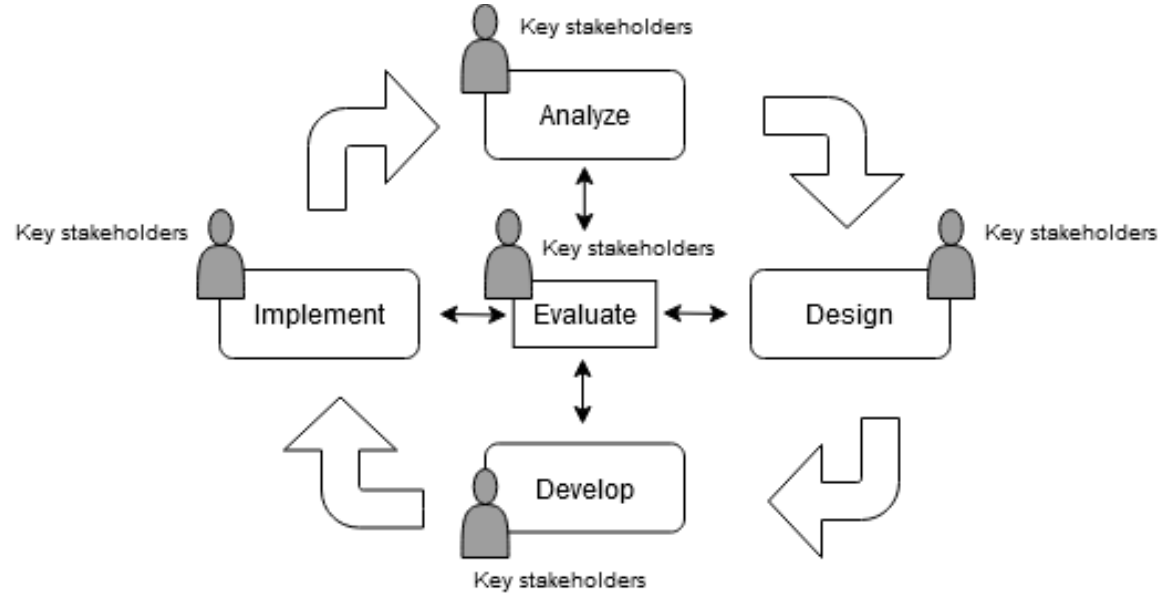

Figure 3. Conceptual model of stakeholder mapping on curriculum development stages.

In the next step the above approach has been used for Supply Chain and Logistics graduate programme. In the last two decades the programme has evolved from being mainly operations research focused in the beginning, through being focused on business logistics, while in the last few years the programme shifted to a broader area of supply chain and logistics, hence the current name of the programme. During the evolution of the programme, various internal and external stakeholders have been involved in its development and the development of its curriculum. The major reevaluation of the programme happens every three to five years which is in line with recommendations in literature (Khan \& Law, 2015). The following analysis is focused on the last such reevaluation and identifies the stakeholders that were involved in it.

Out of internal stakeholder groups the academic staff are involved in every step of the curriculum design. While some phases such as analysis include only a smaller group of academic staff from the key domains covered in the programme led by the management (vicedean for teaching), the latter phases include academics with the expertise from the fields covered in the programme. Another key internal stakeholder group are administrative staff, especially the quality assurance office and student's affairs office, providing the relevant information about the boundary conditions set either by external stakeholders such as the 
governmental regulators, accreditation agencies or internal rules, especially in the analysis phase and to some extent the implementation phase for the purposes of curriculum accreditation. Heads of academic departments together with human resources office are another key stakeholder, working with the curriculum development team on assessment and analysis of staff capacity during the implementation phase.

Several external stakeholders are also a part of curriculum development. Current students are a part of quality assessment activities during the implementation and evaluation phases. These assessments are twofold. One type are the student surveys taken at the end of each course during the evaluation phase, while the other type are students as members of the programme steering committee which provides feedback about the programme during design, development and evaluation phases. The steering committee also includes representatives from other external stakeholder groups: employers, employment agencies, alumni and professional associations. Besides being members of the formal bodies (such as a steering committee), particular groups of external stakeholders are also informally consulted throughout analysis, design, development and evaluation phases. These stakeholders are usually employers, employment agencies, non-governmental organizations and professional associations, as they can provide the most relevant feedback on labor market needs for a particular domain area.

Ensuring success of such engagement requires providing an environment in which stakeholders, especially external ones, will willingly participate. One of such strengthening mechanisms is engaging external stakeholders with the programme through other means first, such as through guest lectures, student projects, alumni, competence centres, professional events etc. This might be more easily accomplished in certain disciplines and programmes, such as business education, and the lack of such activities might provide a serious barrier for stakeholder engagement in curriculum development.

\section{Conclusion}

In this paper a conceptual framework for inclusion of various stakeholders in curriculum development cycle for graduate business programmes is developed by applying the stakeholder map to curriculum development cycle. This is an approach that can further enhance the curriculum development phases by identifying the key stakeholders for each phase ex-ante and including them in the actual process of curriculum development. The main desired outcome of such close ties between curriculum design and stakeholder engagement is an opportunity to close the gap between the contents of a specific programme and the market needs. Opportunities for further research lie in validating the proposed framework on different graduate programmes while also including engagement mechanisms in the framework and exploring barriers for actual stakeholder involvement. 


\section{References}

AACSB International. (2020). 2020 Guiding Principles and Standards (pp. 1-55).

Al-Jubran, K. M. (2020). A stakeholders approach for curriculum development of master's degree in molecular diagnostics. Advances in Medical Education and Practice, 11, 683691. doi: 10.2147/AMEP.S261628

Benckendorff, P., Whitelaw, P., Dredge, D., Day, M., Gross, M., Walo, M., \& Weeks, P. (2012). A stakeholder approach to curriculum development in tourism, hospitality and events (TH\&E) education. 3(3), 1-41.

Chapleo, C., \& Simms, C. (2010). Stakeholder analysis in higher education a case study of the University of Portsmouth. Perspectives: Policy and Practice in Higher Education, 14(1), 12-20. doi: 10.1080/13603100903458034

Fagrell, P., Fahlgren, A., \& Gunnarsson, S. (2020). Curriculum development and quality work in higher education in Sweden: The external stakeholder perspective. Journal of Praxis in Higher Education, 2(1), 28-45. doi: 10.47989/kpdc62

Freeman, R. E. (2010). Strategic management: A stakeholder approach. Cambridge University Press.

Jongbloed, B., Jürgen, E., \& Salerno, C. (2008). Higher Education and Its Communities : Interconnections, Interdependencies and a Research Agenda. Higher Education, 56(3), 303-324. doi: 10.1007/s10734-008-9128-2

Keogh, J. J., Fourie, W. J., Watson, S., \& Gay, H. (2010). Involving the stakeholders in the curriculum process: A recipe for success? Nurse Education Today, 30(1), 37-43. doi: 10.1016/j.nedt.2009.05.017

Kettunen, J. (2015). Stakeholder relationships in higher education. Tertiary Education and Management, 21, 56-65. doi: 10.1080/13583883.2014.997277

Khan, M. A., \& Law, L. S. (2015). An integrative approach to curriculum development in higher education in the USA: A theoretical framework. International Education Studies, 8(3), 66-76. doi: 10.5539/ies.v8n3p66

Lagoke, O., Adesola, S., \& Soname, S. (2020). Social network analysis as a methodological tool to understand university-industry dynamism in enhancing the HEI curriculum-a case of the Nigerian oil industry. Studies in Higher Education, 1-14. https://doi.org/10.1080/03075079.2020.1723529

Matkovic, P., Tumbas, P., \& Sakal, M. (2014). University Stakeholders in the Analysis Phase of Curriculum Development Process Model. Proceedings of ICERI2014 Conference, November, 2271-2277.

Morrison, G. R., Ross, S. J., Morrison, J. R., \& Kalman, H. K. (2019). Designing effective instruction (8th edition). John Wiley \& Sons.

Ornstein, A. C., \& Hunkins, F. P. (2009). Curriculum foundations, principles and issues (5th edition). Allyn and Bacon.

Wagner, N., Hassanein, K., \& Head, M. (2008). Who is responsible for e-learning success in higher education? A stakeholders' analysis. Educational Technology and Society, 11(3), 26-36. 